\title{
Ages and long-term growth patterns of four threatened Vietnamese tree species
}

\author{
Pieter A. Zuidema $\cdot$ Mart Vlam $\cdot$ Pham D. Chien
}

Received: 11 December 2009/Revised: 20 April 2010/Accepted: 21 July 2010/Published online: 6 August 2010

(C) The Author(s) 2010. This article is published with open access at Springerlink.com

\begin{abstract}
Conservation of threatened tree species requires basic information on growth rates and ages. This information is lacking for many species, but can be obtained relatively easily from tree ring analysis. We studied four threatened Vietnamese species: three conifers from highelevation forests (Calocedrus macrolepis, Dacrydium elatum and Pinus kwangtungensis) and one broad-leaved species from lowland forest (Annamocarya sinensis). We collected increment cores from remnant populations in protected areas and measured ring width. We built chronologies and found significant correlations with rainfall (all species) and temperature (two species), indicating that rings were formed annually. Diameter-age trajectories showed that species reached reproductive size at $60-80$ years. Maximum observed ages were 128-229 years. Some species showed large variation in long-term growth rates among individuals, which was partially explained by strong persistence of growth differences. We also assessed whether growth rates changed over time. For certain size categories in some species, we found higher recent growth rates of juvenile trees compared to those in the distant past. This
\end{abstract}

Communicated by A. Braeuning.

Contribution to the special issue "Tropical Dendroecology".

P. A. Zuidema $(\bowtie) \cdot$ M. Vlam · P. D. Chien

Ecology and Biodiversity Group, Institute of Environmental

Biology, Utrecht University, PO Box 80084, 3508 TB Utrecht,

The Netherlands

e-mail: p.a.zuidema@uu.nl

P. A. Zuidema · P. D. Chien

Forest Science Institute of Vietnam, Hanoi, Vietnam

P. D. Chien

Tropenbos Vietnam Programme, Hue, Vietnam shift requires a cautious interpretation, but is consistent with a $\mathrm{CO}_{2}$ fertilization effect. For other size categories, we found contrasting results: extant large trees had higher growth rates as small juveniles compared to extant small trees. Such correlations, which we found for all species, suggest a 'juvenile selection effect': the preferential survival of fast-growing juveniles to the canopy. Information on ages, historical growth rates and juvenile selection effect is relevant for the planning of conservation actions.

Keywords Autocorrelated growth - Dendroecology · Juvenile selection effect . Threatened species · Tree age . Vietnam

\section{Introduction}

Deforestation, overexploitation and forest fragmentation in southeast Asia have led to dramatic population declines of thousands of tree species (Sodhi et al. 2004). As a consequence, a large number of tropical Asian tree species has now been included in the IUCN red list (IUCN 2009). To design effective conservation measures for these species, basic knowledge on their ecology and life history is required (Schemske et al. 1994). For instance, information is required on the ages at which they reach reproductive size, maximum ages, long-term growth rates and responses to climatic variability and changes. Tree ring analysis can assist in obtaining such basic information, as it allows the lifetime reconstruction of growth rates of individual trees (Roig et al. 2005; Brienen and Zuidema 2006; Newton 2007; Soliz-Gamboa et al. 2010). Tree ring data obtained from increment cores can be obtained without harming trees, and is therefore particularly suitable for the study of threatened tree species (e.g., Buckley et al. 2007). 
Compared to permanent plot studies, tree ring analysis is a low-cost tool that requires much less investment of research time. Yet, surprisingly few dendro-ecological studies have been conducted on threatened tree species (Devall et al. 1998; Roig et al. 2005; Lisi et al. 2008).

Although the field of tropical dendro-ecology is relatively young, recent studies have yielded interesting ecological insights that are relevant to understanding the dynamics of threatened tree species (Rozendaal and Zuidema 2010). For instance, it was shown that individual growth trajectories might differ strongly and persistently among individuals (Brienen et al. 2006, 2010), suggesting that variation in environmental conditions of trees (perhaps in combination with genetic differences) may have a lasting impact on growth. Such persistent growth differences may have important consequences for population dynamics and conservation (e.g., Zuidema et al. 2009). A study by Rozendaal et al. (2010a) found that extant large individuals (that have reached the canopy) were the relatively faster growers in the past as a juvenile, a finding that had been observed earlier in temperate forest species (Landis and Peart 2005). A final recent finding is that growth rates in some Bolivian tree species have increased over the last one to two centuries, perhaps as a result of climatic changes (Rozendaal et al. 2010a). Such long-term growth patterns are of importance in understanding the drivers of tree growth in (threatened) tree species.

In this study, we investigated the ages and long-term growth patterns of four threatened tree species in Vietnam (Chien et al. 2008). As a result of large-scale deforestation and unsustainable forest exploitation, over 300 tree species in Vietnam are threatened (Chien 2006). Relict populations often occur in national parks or in remote, hilly areas. We were specifically interested in obtaining relevant information on ages and long-term growth rates of threatened tree species. To this end, we determined the maximum observed age and age at first reproduction of our study species. Furthermore, we reconstructed individual growth trajectories and analyzed to what extent growth rates were autocorrelated over time, meaning that fast growers remained fast growers and slow growers remained slow growers. Next, we checked for gradual changes in diameter growth over time, and compared diameter growth rates obtained from ring analysis with values from permanent sample plots (Chien et al. 2008). To our knowledge, this is one of the first dendro-ecological studies for tropical Asian species (Baker et al. 2005; Buckley et al. 2007) and the first of its kind on threatened tree species.

\section{Materials and methods}

Study site and species

The study was carried out in four protected areas in Vietnam (Table 1). The structure of the coniferous forests (e.g., canopy layers, species diversity) is simpler than that of the lowland forests, where Annamocarya occurs. The canopy of the coniferous forest is also lower and more open than that of the Annamocarya forest.

The precipitation is high in the four study areas: around 2,000 $\mathrm{mm} \mathrm{year}^{-1}$ in $\mathrm{Ba} \mathrm{Vi}$, Cuc Phuong and Hang kia-Pa Co, and more than 3,000 $\mathrm{mm} \mathrm{year}^{-1}$ in Bach Ma. In all four areas, rainfall is not evenly distributed over the year. The dry season is rather pronounced in all areas with 5 dry months $\left(<100 \mathrm{~mm} \mathrm{mo}^{-1}\right)$ in $\mathrm{Ba} \mathrm{Vi}, 6$ in Cuc Phuong and Hang Kia-Pa Co and 3 in Bach Ma.

We studied four Vietnamese tree species: Annamocarya sinensis, Calocedrus macrolepis, Dacrydium elatum and Pinus kwangtungensis (hereafter referred to by their genus names). All four species are long-lived and reach the forest canopy when mature. Three species (Calocedrus, Dacrydium and Pinus) are conifers, while Annamocarya is a broad-leaved deciduous species. The coniferous species grow in subtropical forests in high mountains, while the broad-leaved Annamocarya occurs in lowland tropical

Table 1 Characteristics of study species and field sites

\begin{tabular}{llllllll}
\hline Species (family) & $\begin{array}{l}\text { Maximum } \\
\text { height }(\mathrm{m})\end{array}$ & $\begin{array}{l}\text { Maximum } \\
\mathrm{DBH}(\mathrm{cm})\end{array}$ & $\begin{array}{l}\text { Maximum } \\
\text { age (year) }\end{array}$ & $\begin{array}{l}\text { Reproductive } \\
\text { age (year) }\end{array}$ & $\begin{array}{l}\text { Location } \\
\text { (coordinates) }\end{array}$ & $\begin{array}{l}\text { Altitude } \\
(\mathrm{m})\end{array}$ & $\begin{array}{l}\text { Canopy } \\
\text { height }(\mathrm{m})\end{array}$ \\
\hline $\begin{array}{l}\text { Annamocarya sinensis (Dode) } \\
\text { Leroy (Juglandaceae) }\end{array}$ & 35 & 150 & $>250$ & 56 & Cuc Phuong $\left(21^{\circ} \mathrm{N}-105^{\circ} \mathrm{E}\right)$ & 250 & $25-30$ \\
$\begin{array}{l}\text { Calocedrus macrolepis Kurz } \\
\text { (Cupressaceae) }\end{array}$ & $15-25$ & $>100$ & $>300$ & 68 & Ba Vi $\left(21^{\circ} \mathrm{N}-105^{\circ} \mathrm{E}\right)$ & 1,200 & $15-20$ \\
$\begin{array}{l}\text { Dacrydium elatum (Roxb) Wall ex } \\
\text { Hook (Podocarpaceae) }\end{array}$ & $20-25$ & $50-70$ & $>200$ & 72 & Bach Ma $\left(16^{\circ} \mathrm{N}-107^{\circ} \mathrm{E}\right)$ & 1,200 & $15-20$ \\
$\begin{array}{c}\text { Pinus kwangtungensis Chun ex } \\
\text { Tsiang (Pinaceae) }\end{array}$ & $15-20$ & 80 & $>200$ & 56 & Hang Kia $-\mathrm{Pa} \mathrm{Co}\left(20^{\circ} \mathrm{N}-104^{\circ} \mathrm{E}\right)$ & 1,100 & $15-20$ \\
\hline
\end{tabular}

Age at reaching reproductive size is based on the diameter at breast height $(\mathrm{DBH})$ at which $50 \%$ of the individuals are reproductive $(\mathrm{Chien}$ et al. 2008). Maximum height and DBH are based on Chien (2006), and age at maximum DBH is estimated based on Fig. 1. Altitude and canopy height are for plots 
forests. Several characteristics of the four species and their field sites are described in Table 1.

\section{Data collection}

For the demographic study, we established permanent plots at the study sites in 2003. The following measurements were taken for all individuals $>1$ diameter at breast height $(\mathrm{DBH})$, total height and signs of reproduction (flowers, fruits). These measurements were repeated in 2004 and 2005 (Chien et al. 2008). The relation between reproductive status and DBH was analyzed using logistic regression; this yielded the probability of reproduction for each $\mathrm{DBH}$ (results presented in Chien et al. 2008).

For the dendrochronological study, we collected increment cores from a selection of trees using a hand drill in 2004 and 2005. Adult trees (mostly $>30-\mathrm{cm} \mathrm{DBH)} \mathrm{were}$ selected that had round boles, occurring both inside and outside the plots. From each tree, we extracted one to two wood cores from the stem at approximately $1.3 \mathrm{~m}$ above the ground. We sampled a total of 29 Annamocarya trees, 28 Calocedrus trees, 34 Dacrydium trees and 25 Pinus trees.

All cores were sanded until we could clearly identify the rings. Ring boundaries were identified visually by a magnifier. Ring widths were measured to the nearest $0.1 \mathrm{~mm}$. When the cores did not include the tree pith, the distance to the pith was estimated using the average number of rings of the other samples of the same species. In this way, we obtained an estimate of the number of missing rings. However, often cores taken from hollow trees or cores that deviated far from the pith were eliminated. For the trees having two cores, the average values of these cores were taken to describe average diameter increment. In total, we obtained and measured 30 cores for Annamocarya, 28 for Calocedrus, 42 for Dacrydium and 26 for Pinus (Table 2).

To examine the relationship between climate of the study sites and tree growth for the four species, meteorological data were collected. Annual rainfall data were obtained from the following meteorological stations: Nho Quan for Annamocarya, Son Tay for Calocedrus, Nam
Dong for Dacrydium, and Mai Chau for Pinus. Annual temperature data were collected from Lang station for Anamocarya and Calocedrus, Hue station for Dacrydium and Hoa Bihn station for Pinus.

\section{Dendrochronological data analysis}

For each species, we first checked ring series of all trees for measurement errors (wedging or missing rings) by correlating the series in COFECHA (Grissino-Mayer 2001). Tree ring series that showed strong correlation with each other were selected to establish a chronology. For this purpose, the raw ring series were standardized with a negative exponential curve or negative linear function using ARSTAN (Cook and Holmes 1985). These standardized series were then correlated to the total annual rainfall and average annual temperature (Pearson correlations).

Tree growth analyses

To assess to the extent which growth differences among individuals persisted over time, we correlated the ranks of growth rates across diameter categories. For this purpose, we first calculated the average growth rate of $5-\mathrm{cm}$ diameter categories for each individual (i.e., for $0-5$, $5-10,10-15 \mathrm{~cm}$, etc.) to obtain a data set of average growth in 5-cm categories. Using this data set, we calculated the extent to which the ranks of individuals in terms of growth rates in a particular size category were correlated with those in the successive categories. We performed Spearman correlations among all size categories that contained $>10$ individuals.

The second analysis of growth patterns involved a test for historical changes in growth rates. To this end, we calculated the average growth rate per $2-\mathrm{cm}$ diameter category and for each section we also determined the average diameter and the average year of ring formation. The latter was transformed to year before present (YBP), with 2005 as the reference year. We then correlated average growth in each category to the year before present (YBP) to test for historical changes in growth rates. Negative correlations

Table 2 Descriptive statistics of the tree ring chronology of four Vietnamese tree species

\begin{tabular}{llllllll}
\hline Species & Period & $\begin{array}{l}\text { No. of radii in chronology } \\
\text { (total no. of radii) }\end{array}$ & $\begin{array}{l}\text { Mean ring } \\
\text { width (mm) }\end{array}$ & $\begin{array}{l}\text { Mean } \\
\text { sensitivity }\end{array}$ & SD & $\begin{array}{l}\text { First-order } \\
\text { autocorrelation }\end{array}$ & $\begin{array}{l}\text { Variance first } \\
\text { eigenvector (\%) }\end{array}$ \\
\hline Annamocarya sinensis & $1898-2003$ & $18(30)$ & 2.74 & 0.089 & 0.13 & 0.57 & 23.5 \\
Calocedrus macrolepsis & $1950-2003$ & $8(28)$ & 1.40 & 0.15 & 0.18 & 0.39 & 35.5 \\
Dacrydium elatum & $1837-2003$ & $14(42)$ & 1.37 & 0.11 & 0.16 & 0.68 & 20.8 \\
Pinus kwangtungensis & $1811-2003$ & $20(26)$ & 1.81 & 0.11 & 0.18 & 0.71 & 43.5 \\
\hline
\end{tabular}

The number of individual trees and radii in the chronology (and total number) are given. Mean sensitivity and SD refer to the ring width values in the standard chronology. First-order autocorrelation is the mean correlation between two subsequent years. Variance first eigenvector is the amount of variance that is explained by the first component of the standard chronology 
are an indication for a historical growth increase (Rozendaal et al. 2010a).

Similar correlations were performed between average growth rate per 2-cm diameter category and the presentday diameter of trees. For example, average growth in the 0-2 cm diameter category for all individuals was correlated with extant diameter of these individuals. Positive correlations between growth rate and extant diameter were indications that a tree with a high extant $\mathrm{DBH}$ had a higher growth rate in the specific diameter category. Repeating the analyses with $5-\mathrm{cm}$ diameter categories instead of 2-cm categories yielded very similar results.

A third analysis involved the comparison of diameter growth obtained from tree ring data with those from permanent plots (Chien et al. 2008). We only used tree ring data from trees $>30-\mathrm{cm}$ diameter, as these are mostly wellestablished adult trees. In this way, we were able to check whether juvenile growth rates of extant large trees were higher than those of present-day juvenile trees. The differences in the way the data were obtained did not allow to statistically test for differences as tree ring data are repeated over size categories while plot data are not. However, a qualitative comparison could be made.

\section{Results}

Results of tree ring analysis

Rings of the four study species were found to be sufficiently clear for marking and counting. For each of the four study species a standardized tree ring chronology was created using ARSTAN. Descriptive statistics of the chronology are included in Table 2.

Year-to-year variation in ring width of all species significantly correlated with total annual rainfall in the year of ring formation: Annamocarya $\left(R^{2}=0.57, P<0.01\right)$, Calocedrus $\left(R^{2}=0.15, P<0.05\right)$, Dacrydium $\left(R^{2}=0.21, P<0.05\right)$ and Pinus $\left(R^{2}=0.23, P<0.01\right)$. We also found significant negative correlations between ring width and average annual temperature for Calocedrus $\left(R^{2}=0.12, P<0.05\right)$ and Pinus $\left(R^{2}=0.27, P<0.01\right)$, but not for Anamocarya and Dacrydium. In all, clarity of the rings produced and the correlation of ring widths with annual climate data provides support for the annual nature of the growth rings.

Age-diameter relationships and autocorrelated growth

The four species show distinct differences in growth trajectories and maximum age. Maximum age of the sampled trees ranged from 128 years for an Annamocarya tree of 48.5-cm DBH to 229 years for a Pinus of 78.3-cm DBH (Table 1). The broad-leaved Annamocarya tree showed a higher lifetime growth rate $(\sim 0.5 \mathrm{~cm} /$ year $)$ than the three coniferous species ( $\sim 0.3 \mathrm{~cm} /$ year $)$. The diameter at which $50 \%$ of the individuals were reproductive, ranged from 16 to $34 \mathrm{~cm}$ in the study species. In spite of the differences in growth rate and size at first reproduction, all four tree species reached reproductive size at approximately the same age, 60-80 years (Fig. 1).

Growth trajectories were very similar for Calocedrus individuals, leading to a low degree of variation in ages on
Fig. 1 Growth trajectories of four Vietnamese tree species based on tree ring measurements. Diameter is approximately at breast height (DBH, at $1.3 \mathrm{~m})$. The dashed line indicates the $\mathrm{DBH}$ at which $50 \%$ of the individuals are reproductive (based on a logistic regression in Chien et al. 2008)
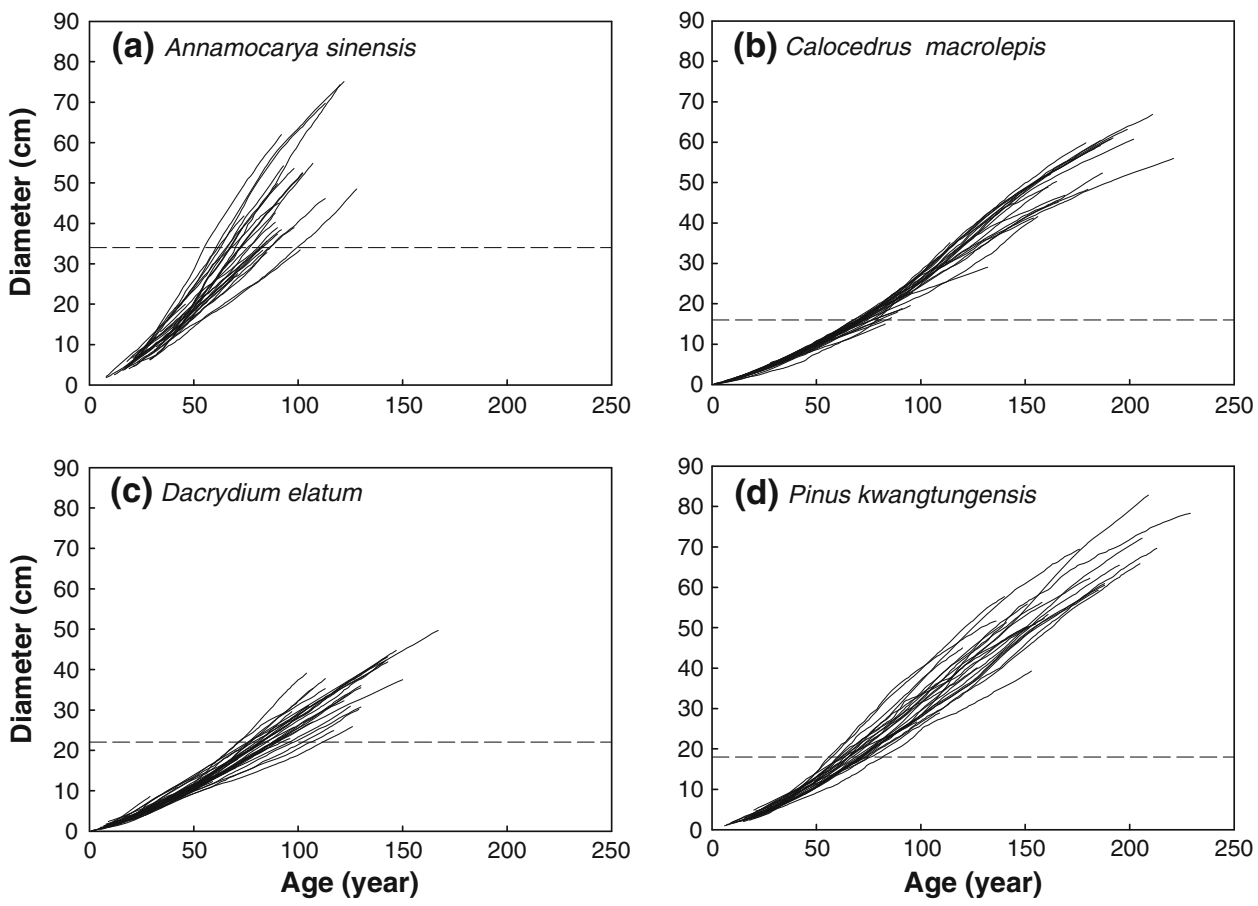
reaching reproductive diameter. A contrasting pattern was observed for Annamocarya for which individual growth trajectories strongly varied, resulting in high age variability on reaching reproductive size and the typical fan-shaped figure (see Fig. 1a). Pinus and Dacrydium showed an intermediate degree of variation across individuals. Another observation that can be made based on these growth trajectories is that for Annamocarya and Dacrydium, fast-growing trees tend to remain the faster growers over several decades, while in the other two species, individual growth curves tend to show more crossing over.

The latter observation on the degree to which fast growers remain fast growing was evaluated by calculating the degree of autocorrelation. Figure 2 shows the results of rank correlations, which reveal the extent to which the ranking of individuals according to their growth rate is maintained over diameter categories. For instance, Fig. 2a shows that for Annamocarya, the ranking of individuals in the $5-10 \mathrm{~cm}$ category is strongly related to that in the $10-15 \mathrm{~cm}$ category, and also maintained in diameter categories of $15-20,20-25,25-30$ and $35-40 \mathrm{~cm}$. For practical reasons, we show correlations for $5-\mathrm{cm}$ wide categories, but $2-\mathrm{cm}$ wide categories gave similar results.

The results of these autocorrelation analyses show that ranks in growth rate are very often maintained over one or two 5-cm diameter categories (Fig. 2). Thus, growth differences persisted at least for one or two decades for all species. In Annamocarya and Dacrydium, growth differences persisted over more diameter categories, with positive rank correlations extending from the 5-10 cm category onwards. Such correlations imply that growth differences were persistent for many decades.

\section{Historical versus recent growth rates}

We were interested to know whether growth rates for a given diameter range had changed over time. We evaluated this for 2-cm wide diameter categories, over the entire diameter range of all four species. An example of these analyses is shown in Fig. 3 for the relation between diameter growth in the $12-14 \mathrm{~cm}$ diameter category and year before present (YBP). In this particular size category,
Fig. 2 Rank correlations (Spearman's $\rho$ ) of diameter growth rates between subsequent diameter categories for four Vietnamese tree species. Positive significant correlations (gray cells) indicate that the ranking of growth rates in a given diameter category is maintained in the next or further category. Negative significant correlations (hatched cells) indicate that ranking is reversed. Blank cells indicate that no correlation was performed (for $n<11$ ) or that correlations were nonsignificant $(P>0.05)$. The bordering line includes all possible correlations (a) Annamocarya sinensis

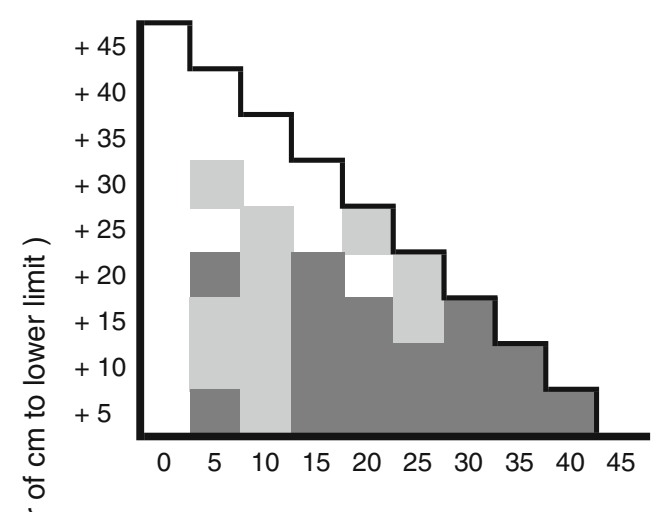

(c) Dacrydium elatum

政

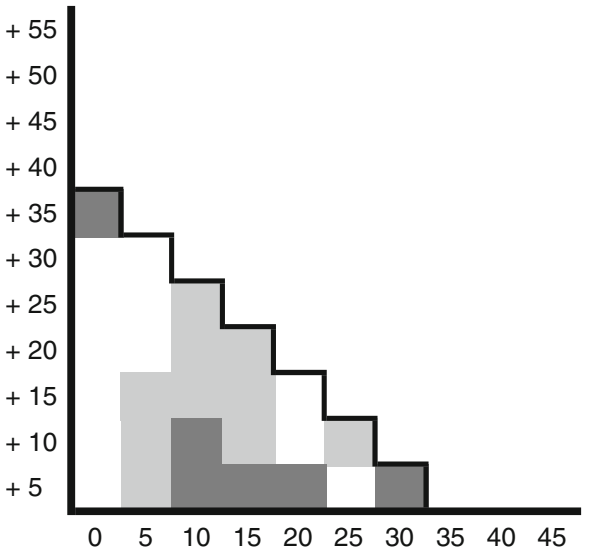

(b) Calocedrus macrolepis

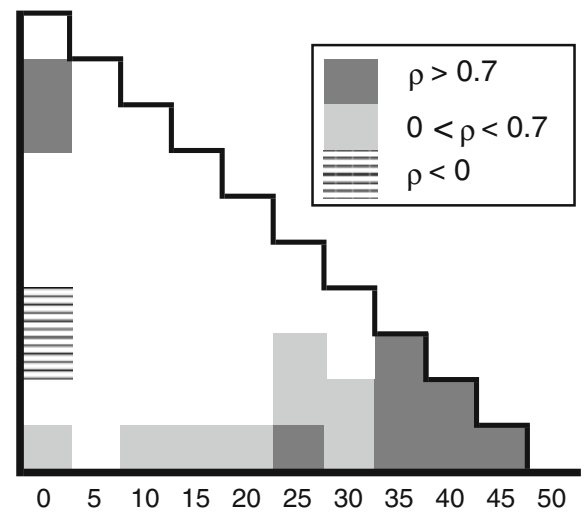

(d) Pinus kwangtungensis

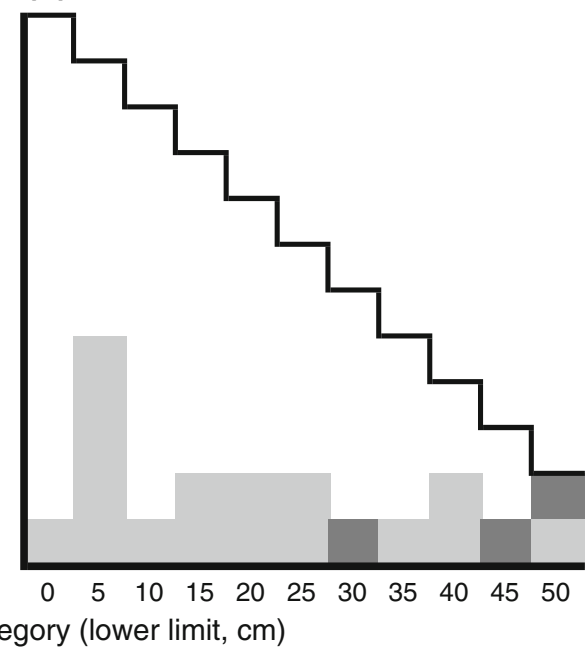


Fig. 3 Relation between diameter growth in the $12-14 \mathrm{~cm}$ diameter category and year before present (2005). Each point represents one individual tree. Spearman $\rho$ is given, as well as significance: $* P<0.05$, ** $P<0.01$. The $12-14 \mathrm{~cm}$ category is taken as an example; correlations for other size categories are included in Fig. 5. Note scale differences across species on $x$ - and $y$-axes

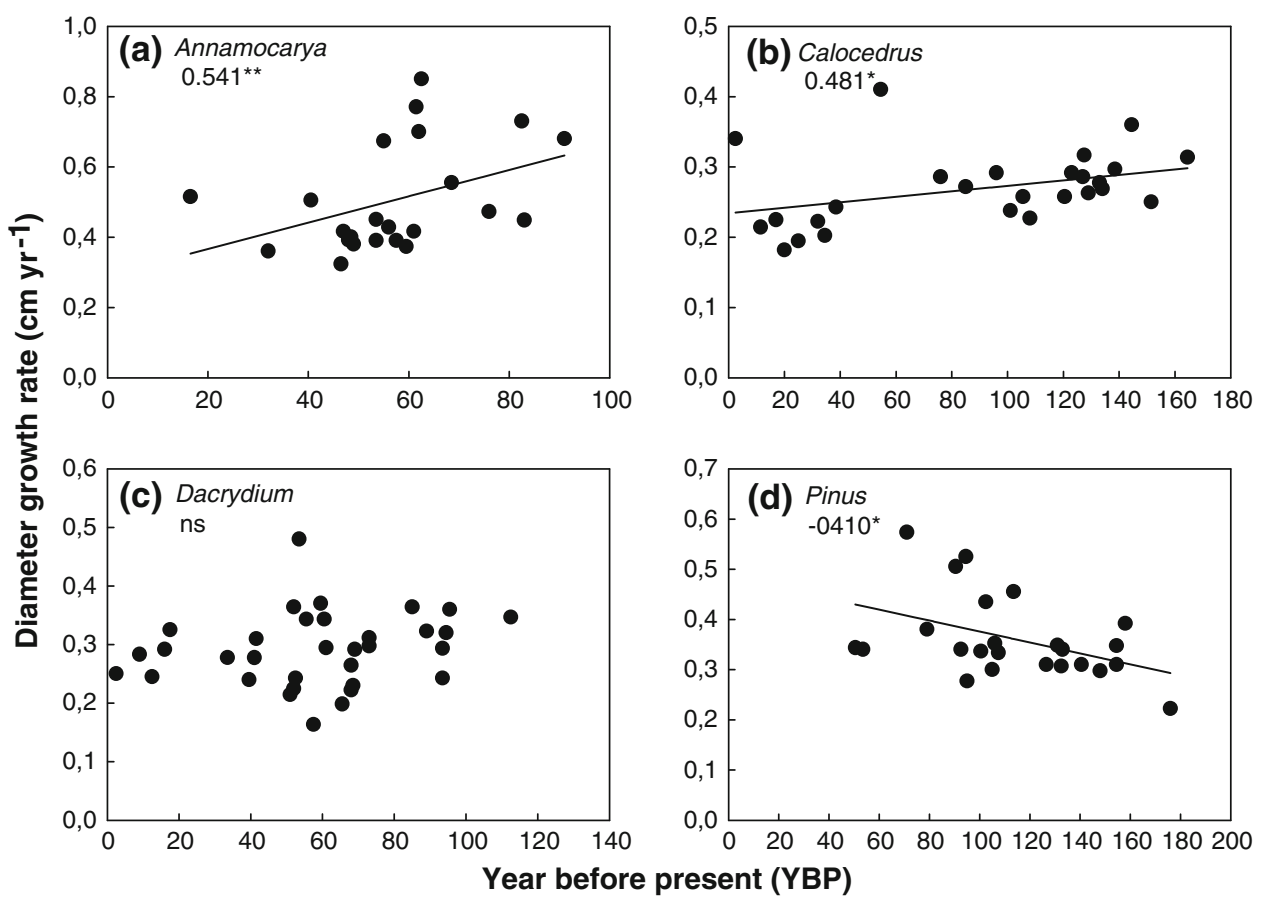

we found a significant negative relation between growth and YBP for Pinus (Fig. 3d), suggesting that growth rates in the recent past were higher than those in the distant past. For Annamocarya and Calocedrus, we found the opposite result: diameter growth in this size category was lower in recent years than before (Fig. 3a, b).

Another way of analyzing historical changes in diameter growth rates is to relate these rates to the present-day diameter of the tree. If such relations are significant, this may indicate that the large trees of today have been the fast growers in the past. Figure 4 shows examples of the relations between growth in the $12-14 \mathrm{~cm}$ diameter category and extant diameter. For three of the four species positive relations were found, indicating that juvenile growth rates have been higher for trees that are currently large. Comparing these results with those of the growth-YBP relations in Fig. 3 reveals that for Annamocarya and Calocedrus, the positive growth-diameter relations corresponded with negative growth-YPB relations. But for the other two species, the results differ.

Apart from the example size categories for which results are shown in Figs. 3 and 4, we also correlated growth to YBP and extant diameter for all 2-cm diameter categories for which sufficient data were available. These results are summarized in Fig. 5. Overall, we found a close correspondence between growth-YBP correlations and growthdiameter correlations. Further, a general pattern is observed in Fig. 5 of significant positive correlations for large diameter categories, while two of the species (Dacrydium and Pinus) show significant negative correlations for small diameter categories $(<12 \mathrm{~cm})$.
Finally, we also compared growth rates obtained from field measurements with those from tree ring data. Results suggest that growth rates of juvenile trees (DBH $<20 \mathrm{~cm}$ ) were generally higher for extant large trees (i.e., ring data) than extant small trees (i.e., plot data), see Fig. 6. For instance, juvenile growth rates of extant large Anamocarya and Pinus trees were on average twice as high as those of currently small trees in the plots. The same pattern of higher juvenile growth, although less clear, is observed for extant large Calocedrus and Dacrydium trees in part of the juvenile size categories. In addition, we found some marked but inconsistent growth differences between plot and ring data for larger size categories in Dacrydium and Pinus.

\section{Discussion}

Age estimates and climate-growth relations

Maximum observed ages of our study species ranged from 130 to 230 years, while estimated maximum ages based on growth trajectories and the largest observed diameter were $>200$ years for all species and $>300$ years for Calocedrus. These maximum ages are within the range of published ages based on ring counts for (sub)tropical tree species (Martinez-Ramos and Alvarez-Buylla 1998, Rozendaal et al. 2010).

The average diameter at which reproduction starts varied quite strongly among species, from 18 to $34 \mathrm{~cm}$, but in all species this size was reached at comparable ages of 
Fig. 4 Relation between diameter growth in the $12-14 \mathrm{~cm}$ diameter category and extant diameter of four Vietnamese tree species. Each point represents one individual tree. Spearman $\rho$ is given, as well as significance: $* P<0.05$, $* * P<0.01$. The $12-14 \mathrm{~cm}$ category is taken as an example; correlations for other size categories are included in Fig. 5. Note scale differences across species on $x$ - and $y$-axes

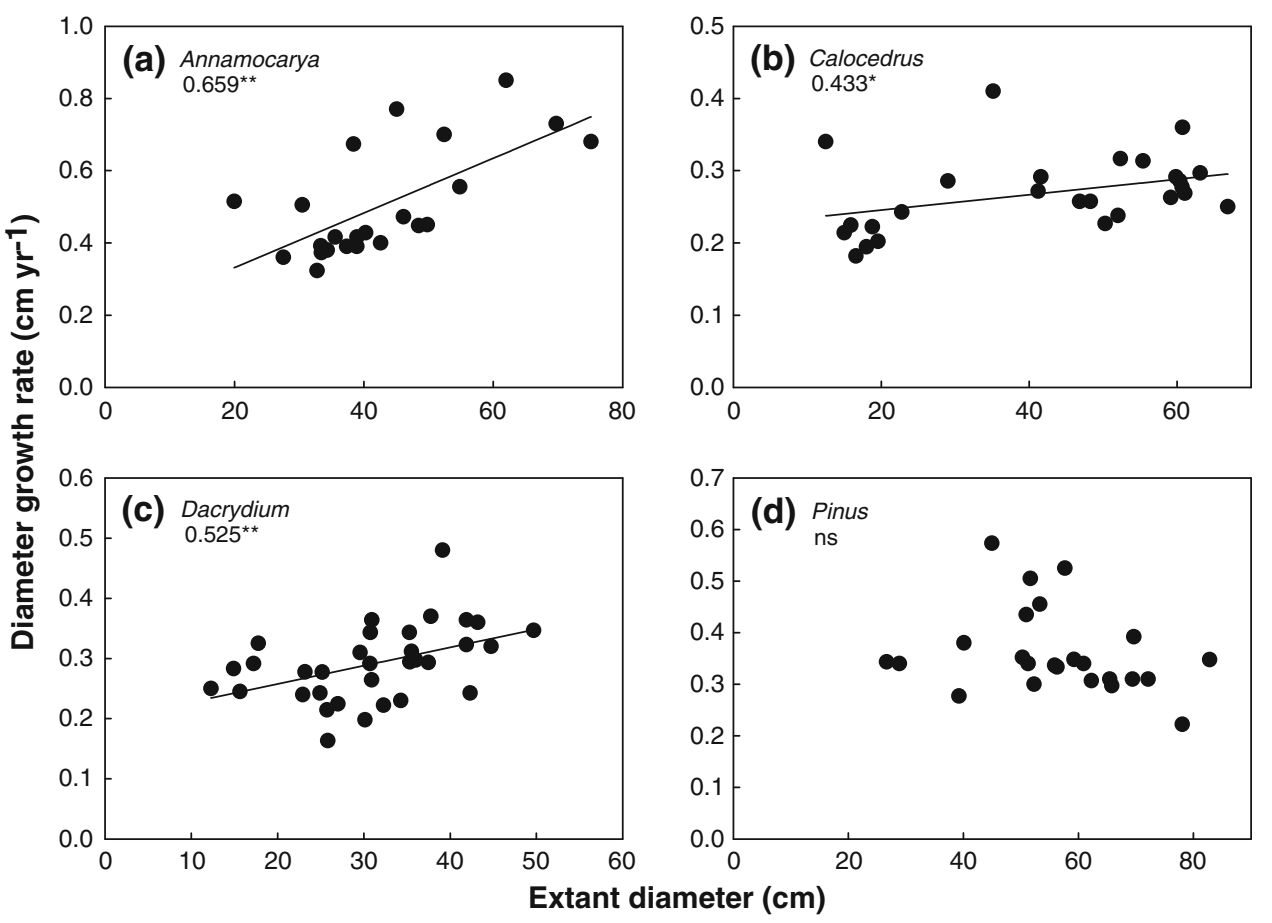

Fig. 5 Spearman's correlation coefficients between diameter growth, extant diameter at breast height (DBH, circles) and year before present (YBP, squares) for 2-cm diameter categories. Nonsignificant correlations are indicated by open symbols, and significant correlations $(P<0.05$, 2-tailed $)$ are indicated by filled symbols. YBP is expressed as the number of years before present (we took the average for all rings per diameter category). Sample sizes are indicated in the lower part of the graphs
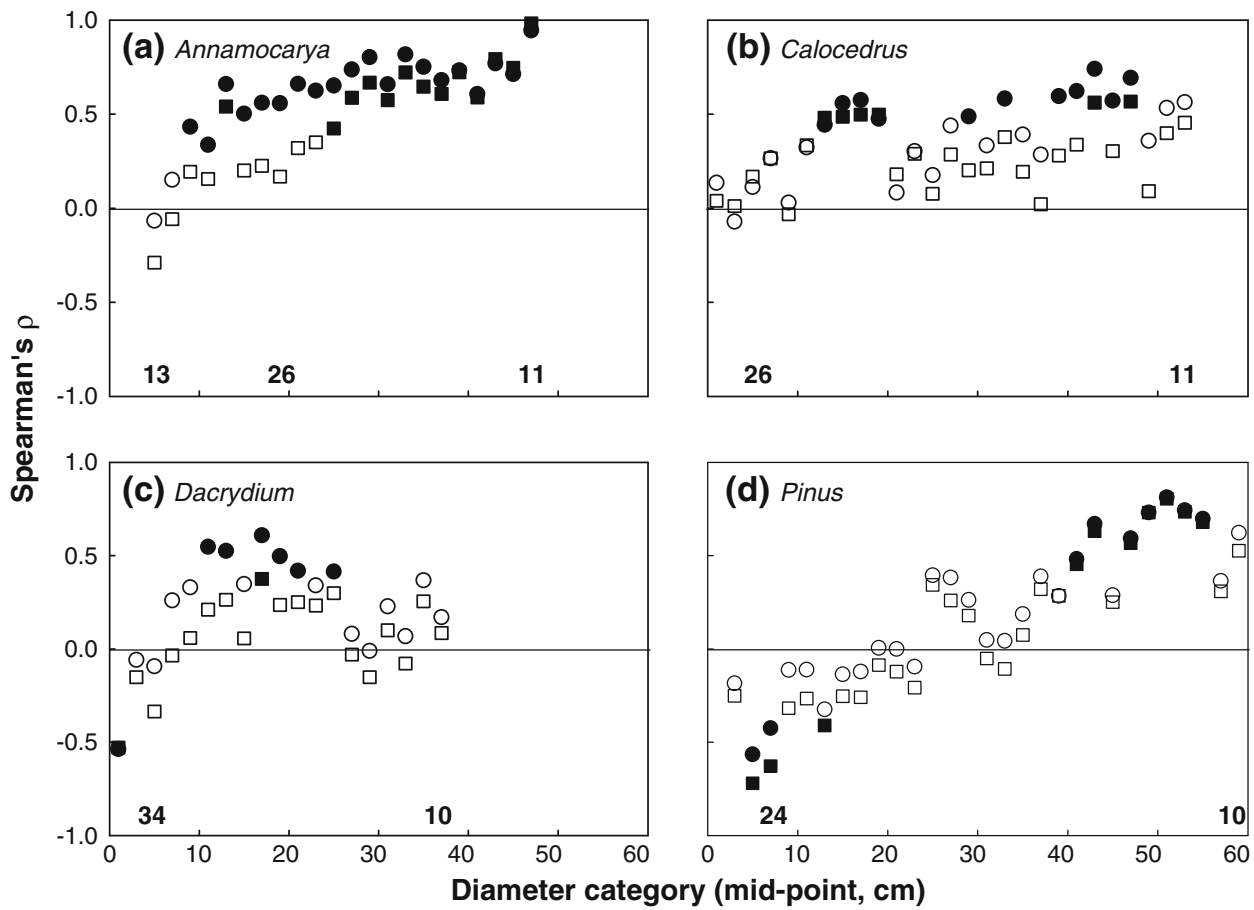

60-80 years. These observed ages are in accordance with previously published age estimates based on matrix models (Chien et al. 2008), but low compared to some other (sub)tropical tree species (e.g., Zuidema and Boot 2002). While the age at reaching reproductive size is low, very few seedlings reach that age. For our study species, the survival probability of a seedling to reach 60 years was estimated to be $<0.1 \%$ for Calocedrus and $<1 \%$ for the other three species (Chien et al. 2008). Therefore, conservation efforts that increase this success rate likely have a large impact on population growth.

The long reproductive period of our study species provides some security for long-term maintenance of the small relict populations of our study species. Yet, demographic 
Fig. 6 Comparison of diameter growth rates from permanent plot measurements (filled dots) and tree ring width (open dots) for $n_{\text {trees }}>5$. Symbols represent mean diameter growth for $5-\mathrm{cm}$ diameter categories; error bars indicate $95 \%$ confidence interval

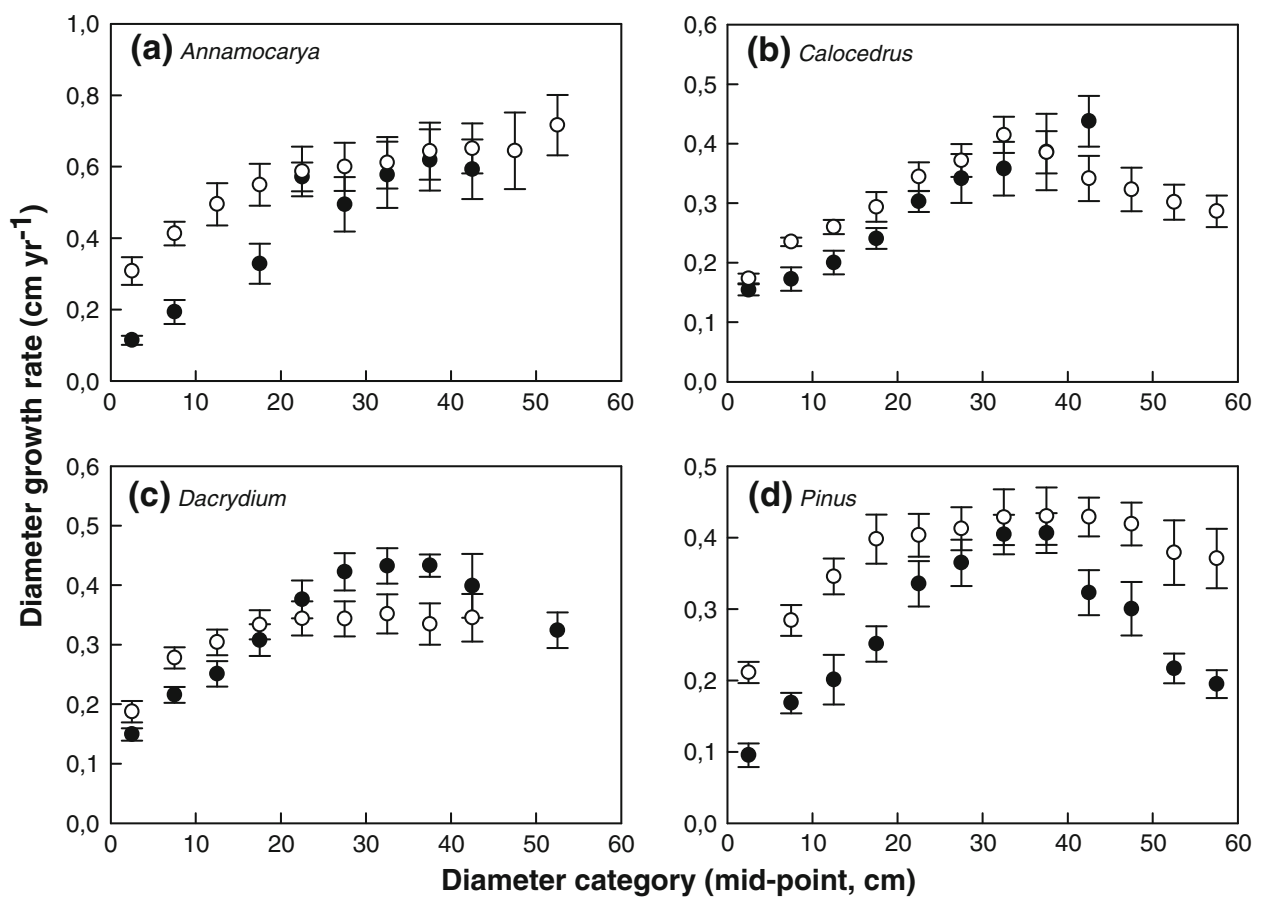

analyses conducted so far suggest population decline for these and other threatened tree species in Vietnam (Chien et al. 2008; Zuidema et al. 2010). In this context, any conservation effort that prevents anthropogenic mortality of juvenile and adult trees will likely have a positive effect on the resilience of these populations.

\section{Long-term growth patterns}

We found that differences in growth rates among individuals tended to persist for one or several decades in most size categories for all species. Thus, fast growers tend to remain fast growers and slow growers tend to remain slow growers. For Annamocarya and Dacrydium, growth differences were often maintained over various size classes, implying that they persisted for several decades and probably for $>60$ years. These results are in accordance with those from a number of recent studies in which persistent growth differences were reported over short $(<10$ years, e.g., Grogan and Landis 2009) to long timescales (Brienen et al. 2006, 2010). It is likely that persistent growth differences are commonplace in (tropical) tree species, although the degree of growth differences and the degree of persistence likely differs across species and forest types. The occurrence of autocorrelated growth in tree species will have important implications for demographic studies and requires a different approach to demographic modeling (e.g., Van Mantgem and Stephenson 2005; Metcalf et al. 2009; Zuidema et al. 2009).

We found positive relations between diameter growth and extant diameter for all study species (Fig. 5). In three out of four species, such positive correlations were found for relatively small, juvenile trees $(<20-\mathrm{cm}$ diameter, all except Pinus). A similar result was obtained from the comparison of plot and ring data, in which extant large trees showed higher juvenile growth rates compared to extant juvenile trees (Fig. 6). In all, these results are consistent with the pattern that would be expected for a 'juvenile selection effect' (Rozendaal et al. 2010a). Such a 'juvenile selection effect' occurs if fast-growing juveniles have a higher chance to reach adult size as they accumulate less mortality risk while in the vulnerable juvenile stage, compared to slow-growing individuals. Such preferential survival of fast growers has now been reported for a number of species in both temperate and tropical forests (Landis and Peart 2005; Rozendaal et al. 2010a). The species studied here occur in distinct forest types: Annamocarya is a low-land forest tree of closed-canopy forests and fertile soils, while the three coniferous species occur in more open forests with a lower canopy but on rocky substrates. Thus, growth of Annamocarya juveniles is probably mostly light limited, and persistent fast juvenile growth likely increases the chance of reaching the canopy (cf. Rozendaal et al. 2010a). For the coniferous species, limited availability of water and nutrients or a limited rooting volume may lead to similar preferential survival of fast growers to adult size, but information on growth-limiting factors is required for a proper interpretation of these results.

In three of the four species, the correlations between growth and extant diameter were also present for adult trees of 30 to even $60-\mathrm{cm}$ diameter (Fig. 5). It is unlikely that 
preferential survival of fast-growing individuals (the mechanism behind the 'juvenile selection effect') plays a role for trees of these sizes. Individuals of these sizes are well established and experience low mortality risks. An alternative explanation is related to strong and persistent growth differences that we observed (Fig. 2). If fast growers of the past remain fast growers in the present, they may be able to attain larger sizes compared to slow growers. This would be possible if the environmental conditions (e.g., light, water, nutrients) or tree characteristics (e.g., crown size) that allow trees to grow fast also provide the possibility to attain a large size. Another possible explanation of the results is that populations in which we sampled were recovering from previous disturbances and that historical growth conditions differed from present-day conditions (Rozendaal et al. 2010b). In the case of Annamocarya, the forest in the study area may have been more open before the Cuc Phuong National Park was established, allowing for faster growth of juveniles at that time, and gradually slower growth rates toward recent times as the forest became more dense and competition increased. The growth trajectories of Annamocarya presented in Fig. 1a, seem to support this idea. The individual trajectories show very little leveling off, i.e., the graphs are less sigmoid shaped than would be expected from a fully mature population. Therefore, the population may be recovering after a large-scale disturbance. Unfortunately, we did not possess information to evaluate if such changes had taken place and a visual inspection of the data did not reveal clear indications of concurrent recruitment peaks. We are aware that these explanations are rather speculative, but believe that it is important to use the results of this pilot study to formulate new hypotheses that can be tested in future work.

We found negative correlations between diameter growth and year before present, for small diameter categories in two of our study species. This finding is consistent with recent results of a tree ring study in Bolivia (Rozendaal et al. 2010a), in which historical growth increases were observed for juvenile individuals pertaining to four tree species in moist forests. The interpretation of these patterns is not straightforward, as multiple factors may cause juvenile growth rates to increase over time, including $\mathrm{CO}_{2}$ fertilization, recovery from disturbances and sampling effects (Baker 2010; Rozendaal et al. 2010a). In our case, the interpretation was also hampered by the lack of small individuals among the cored trees, which contain growth rates of small trees from the recent past.

Only recently have ecologists started to relate tree growth rates to extant tree size and time before present. This has led to interesting but sometimes puzzling results. It is evident that such analyses need to be conducted on a larger set of species from various forest types to derive general patterns.
Tree ring analysis for conservation

Our study shows that with relatively simple means and in a low-cost study, it is possible to obtain information on ages and long-term tree growth patterns of tree species. Such basic information on ages is of direct relevance for conservation and management of threatened tree species.

The evaluation of historical growth patterns and the comparison of growth rates from tree rings and plot data allowed us to establish that fast-growing juveniles in our study species likely had a higher probability to reach reproductive size. Such persistently fast-growing individuals exhibit very different growth trajectories (Metcalf et al. 2009) and likely have a much larger contribution to population growth than slow growers (Zuidema et al. 2009). For conservation purposes, it will therefore be important to evaluate the factors that allow juvenile individuals to grow fast and maintain fast growth. Once such factors are identified, fast growers may be recognized and receive particular attention in conservation actions and the development of slower growing individuals may be stimulated.

Acknowledgments We are grateful for the assistance in fieldwork and support from National Park agencies in Vietnam, as well as the Forest Science Institute of Vietnam. Danaë Rozendaal and Claudia Soliz kindly contributed to this study during the data analysis phase. This work has been supported by financial contributions from Tropenbos International (to P.D.C.).

Open Access This article is distributed under the terms of the Creative Commons Attribution Noncommercial License which permits any noncommercial use, distribution, and reproduction in any medium, provided the original author(s) and source are credited.

\section{References}

Baker PJ (2010) Changing juvenile growth patterns in tropical trees: selective effects, history, or both? New Phytol 185:595-598

Baker PJ, Bunyavejchewin S, Oliver CD, Ashton PS (2005) Disturbance history and historical stand dynamics of a seasonal tropical forest in western Thailand. Ecol Mon 75:317-343

Brienen RJW, Zuidema PA (2006) Lifetime growth patterns and ages of Bolivian rain forest trees obtained by tree ring analysis. J Ecol 94:481-493

Brienen RJW, Zuidema PA, During HJ (2006) Autocorrelated growth of tropical forest trees: unraveling patterns and quantifying consequences. For Ecol Manage 237:179-190

Brienen RJW, Zuidema PA, Martinez-Ramos M (2010) Attaining the canopy in dry and moist tropical forests: strong differences in tree growth trajectories reflect variation in growing conditions. Oecologia. doi:10.1007/s00442-009-1540-5

Buckley BM, Duangsathaporn K, Palakit K, Butler S, Syhapanya V, Xaybouangeun N (2007) Analyses of growth rings of Pinus merkusii from Lao P.D.R. For Ecol Manage 253:120-127

Chien PD (2006) Demography of threatened tree species in Vietnam. Dissertation, Utrecht University 
Chien PD, Zuidema PA, Nghia NH (2008) Conservation prospects for threatened Vietnamese tree species: results from a demographic study. Pop Ecol 50:227-237

Cook ER, Holmes RL (1985) Users manual for program ARSTAN. Lamont-Doherty Earth Observatory, Palisades, NY

Devall MS, Parresol BR, Armesto JJ (1998) Dendroecological analysis of a Fitzroya cupressoides and a Nothofagus nitida stand in the Cordillera Pelada, Chile. For Ecol Manage 108:135-145

Grissino-Mayer HR (2001) Evaluating crossdating accuracy: a manual and tutorial for the computer program COFECHA. Tree Ring Bull 57:205-221

Grogan J, Landis RM (2009) Growth history and crown vine coverage are principal factors influencing growth and mortality rates of big-leaf mahogany Swietenia macrophylla in Brazil. J Appl Ecol 46:1283-1291

IUCN (2009) IUCN red list of threatened species. http://www. iucnredlist.org. Accessed 10 December 2009

Landis RM, Peart DR (2005) Early performance predicts canopy attainment across life histories in subalpine forest trees. Ecology $86: 63-72$

Lisi CS, Tomazello M, Botoss PC, Roig FA, Maria VRB, FerreiraFedele L, Voigt ARA (2008) Tree-ring formation, radial increment periodicity, and phenology of tree species from a seasonal semi-deciduous forest in southeast Brazil. IAWA J 29:189-207

Martinez-Ramos M, Alvarez-Buylla ER (1998) How old are tropical rain forest trees? Trends Plant Sci 3:400-405

Metcalf JE, Horvitz CC, Tuljapurkar S, Clark DA (2009) A time to grow and a time to die: a new way to analyze the dynamics of size, light, age, and death of tropical trees. Ecology 90:2766-2778

Newton AC (2007) Forest ecology and conservation: a handbook of techniques. Oxford University Press, Oxford

Roig FA, Jimenez Osornio JJ, Villanueva Diaz J, Luckman B, Tiessen H, Medina A, Noellemeyer EJ (2005) Anatomy of growth rings at the Yucatán Peninsula. Dendrochron 22:187-193
Rozendaal DMA, Zuidema PA (2010) Dendroecology in the tropics: a review. Trees (this issue). doi:10.1007/s00468-010-0480-3

Rozendaal DMA, Brienen RJW, Soliz-Gamboa CC, Zuidema PA (2010a) Tropical tree rings reveal preferential survival of fastgrowing juveniles and increased juvenile growth rates over time. New Phytol 185:759-769

Rozendaal DMA, Soliz-Gamboa CC, Zuidema PA (2010b) Assessing long-term changes in tropical forest dynamics: a first test using treering analysis. Trees (this issue). doi:10.1007/s00468-010-0478-x

Schemske D, Husband BB, Ruckelshaus M, Goodwillie C, Parker I, Bishop G (1994) Evaluating approaches to the conservation of rare and endangered plants. Ecology 75:584-606

Sodhi NS, Kohl LP, Brook BW, Ng KPL (2004) Southeast Asian biodiversity: an impending disaster. Trends Ecol Evol 19:654-660

Soliz-Gamboa CC, Rozendaal DMA, Ceccantini G, Angyalossy V, van der Borg K, Zuidema PA (2010) Evaluating the annual nature of juvenile rings in Bolivian tropical rainforest trees. Trees Struct Funct (this issue). doi:10.1007/s00468-010-0468-Z

Van Mantgem PJ, Stephenson NL (2005) The accuracy of matrix population model projections for coniferous trees in the Sierra Nevada, California. J Ecol 93:737-747

Zuidema PA, Boot RGA (2002) Demography of the Brazil nut tree (Bertholletia excelsa) in the Bolivian Amazon: impact of seed extraction on recruitment and population dynamics. J Trop Ecol 18:1-31

Zuidema PA, Brienen RJW, During HJ, Güneralp B (2009) Do persistently fast-growing juveniles contribute disproportionately to population growth? A new analysis tool for matrix models and its application to rainforest trees. Am Nat 174:709-719

Zuidema PA, Jongejans E, Chien PD, During HJ, Schieving F (2010) Integral projection models for trees: a new parameterization method and a validation of model output. J Ecol 98:345-355 